\title{
PENGARUH KARAKTERISTIK LESI TERHADAP ADEKUASI AMBILAN SAMPEL SITOLOGI PADA TINDAKAN BIOPSI JARUM HALUS TRANSTORAKAL-TUNTUNAN USG
}

\author{
Dini Rachma Erawati* ${ }^{\star 凶}$
}

\begin{abstract}
Abstrak
Biopsi transtorakal untuk lesi perifer memerlukan tuntunan modalitas radiologi dalam pengambilan sampel sitologi. Ultrasonografi (USG) menjadi modalitas pilihan dalam menuntun prosedur biopsi tersebut. Penelitian ini bertujuan menentukan pengaruh karakteristik lesi terhadap adekuasi ambilan sampel sitologi pada tindakan biopsi jarum halus transtorakal dengan tuntunan ultrasonografi. Sebanyak26 pasien dengan lesi paru perifer ditentukan karakteristik lesi berdasarkan posisi, ukuran lesi yang menempel dinding dada, bentuk, ekhogenitas, komponen dominan dan vaskularisasi lesi, lalu dilakukan biopsi jarum halus transtorakal dengan tuntunan USG. Ambilan sampel sitologi yang adekuat ditentukan dengan laporan analisis sitopatologi oleh ahli patologi. Uji bivariat dilakukan an tara karakteristik lesi dengan adekuasi ambilan sampel sitologi yang dituntun USG. Didapatkan $12(46 \%)$ pasien posisinya di anterior, $13(50 \%)$ pasien memiliki ukuran $2-5 \mathrm{~cm}, 22(84,6 \%)$ pasien memiliki bentuk tepi membulat reguler, $20(76,9 \%)$ pasien memiliki ekhogenitas hipoekhoik tanpa bintik hiperekhoik dan $20(76,9 \%)$ pasien terdeteksi adanya vaskularisasi intralesi dengan $\leq 2$ pembuluh darah. Sampel sitologi yang adekuat didapatkan pada 22 $(84,6 \%)$ dari 26 pasien, termasuk satu pasien dengan lesi berukuran kecil $(<2 \mathrm{~cm})$. Tidak ada komplikasi pasca prosedur pada seluruh pasien. Dapat disimpulkan bahwa karakteristik lesi dengan adekuasi ambilan sampel sitologi dengan tuntunan USG tidak memiliki hubungan yang signifikan. Namun, USG tetap merupakan modalitas radiologi pilihan sebagai penuntun tindakan biopsi transtorakal untuk lesi perifer dengan keberhasilan yang cukup baik, bahkan untuk lesi berukuran kecil $(<2 \mathrm{~cm})$.
\end{abstract}

Kata kunci: adekuasi sampel, biopsi, karakteristik lesi, ultrasonografi.

\section{THE EFFECT OF LESION CHARACTERISTICS ON THE ADEQUACY OF CYTOLOGY SAMPLING BY ULTRASOUND GUIDED TRANSTHORACIC FINE-NEEDLE BIOPSY}

\begin{abstract}
Transthoracic biopsy for peripheral lesion needs imaging tool as guidance in order to get representative cytology sample. Ultrasonography (US) has become modality of choice for peripheral lung lesions. The aim of this study was to know the influence oflesion characteristics on adequacy of cytology sampling by FNABUS guided procedure. There were twentysix patientswith peripheral lung lesion underwentFNAB-US guided. The lesion characteristics determined by initial imaging, which were the position, lesions size, contact with thoracic wall, shape, echogenity, dominant component and vascularization. Adequate cy tology sampling determined by pathologist report. Bivariate analysis was applied between two variable. Results showed mostly of the lesion were on the anterior side in $12(46 \%)$ patients, size of lesion contacts with thoracic wall mostly $2-5 \mathrm{~cm}$ in $13(50 \%)$ patients, regular rounded shape were visualized in $22(84,6 \%)$ patients, hypoechoic lesion without hyperechoic dots were seen in $20(76,9 \%)$ patient and vascularization with $\leq 2$ vessels was detected in $20(76,9 \%)$ patients. There were $22(84,6 \%)$ adequate sample from 26 patient, including one patient with small size lesion $(<2 \mathrm{~cm})$. There was no complication in all patients after procedure.There was no significant correlation between lesion characteristics with adequacy cytology sampling in FNAB-US guided procedure. Nevertheless, US is still the modality of choice as guiding tool for transthoracal biopsy for peripheral lung lesions even for small lesion $(<2 \mathrm{~cm})$.
\end{abstract}

Keywords: adequacy sampling, biopsy,lesion characteristic, ultrasonography.

*Departemen Radiologi, Fakultas Kedokteran, Universitas Brawijaya - RSUD Dr. Saiful Anwar Malang

E-mail: dr.erawat@ub.ac.id 


\section{Pendahuluan}

Ultrasonografi sebagai modalitas diagnostik mampu memvisualisasikan lesilesi intratorakal subpleura dengan baik. USG bisa membedakan lesi-lesi ganas dan jinak dengan memperhatikan batas paru, batas lesi, perubahan struktur bronkhus dan pembuluh darah, serta ada atau tidaknya invasi lesi ke struktur sekitar. Massa paru perifer tampil sebagai massa berbatas tegas dengan ekhogenitas yang bervariasi, tersering hipoekhogenik, yang dikelilingi jaringan paru teraerasi dengan refleksifitas yang tinggi. ${ }^{1}$ Lesi jinak seperti pneumonia memiliki karakteristik lesi yang berbeda seperti bentuk dan ekhogenitas serupa organ liver, adanya alveologram dan airbronkhogram, batas yang tidak tegas dan ireguler, dan sirkulasi yang meningkat seragam. ${ }^{2}$

Biopsi perkutan transtorakal dengan penuntun pencitraan merupakan teknik biopsi pada organ toraks yang sudah luas penggunaannya. Teknik biopsi ini bersifat efektif dan invasif minimal dalam rangka penegakan diagnosis beragam lesi intratorakal, yang tidak bisa dijangkau dengan prosedurbronkhoskopi. ${ }^{3}$

Untuk lesi yang menempel dinding dada, bila tidak ada bagian aerasi paru di antara tranduser dan lesi, USG torakal menjadi modalitas yang membantu menuntun tindakan biopsi. Modalitas ini memberikan kombinasi tampilan anatomi cross sectional (temasuk menggambarkan anatomi vascular dengan USG color Doppler dan evaluasi internal echostruktur) dan visualisas ireal-time.$^{4,5}$

Penggunaan USG dalam mengambil contoh jaringan di regio toraks memiliki tantangan tersendin. Hasil tampilan USG tidak dapat memberikan gambaran toraks yang utuh. Hanya lesi yang menempel dinding dada, atau bila lesi disertai media yang mengkonduksikan gelombang suara, seperti cairan efusi pleura atau jaringan paru yang mengalami konsolidasi, yang bisa dievaluasi oleh modalitas USG. Absorpsi gelombang suara oleh tulang, seperti sternum, skapula dan vertebra juga membuat area dibelakang tulang-tulang ini sulit ditampilkan. Namun lesi-lesi di belakang tulang iga bisa disiasati dengan teknik respirasi yang baik. ${ }^{6}$

Rekomendasi dari British Thoracic Society menyebutkan sebisa mungkin biopsi paru transtorakal perkutan menggunakan tuntunan USG sebagai modalitas yang paling aman, cepat dan lebih murah. ${ }^{4}$

Belum banyak penelitian yang dilakukan atas tindakan biopsi perkutan transtorakal dengan tuntunan USG yang terkait karakteristik lesi paru perifer. Tujuan dari penelitian ini adalah menentukan pengaruh karakteristik lesi terhadap adekuasi ambilan sampel sitologi pada tindakan biopsi jarum halus transtorakaltuntunan USG di RSUDDr. Saiful Anwar Malang.

\section{Bahan dan Metode}

Protokol

Penelitian ini dilakukan di Departemen Radiologi RSUD Dr. Saiful Anwar Malang, menggunakan metode analitik observasional dengan rancangan studi cross sectional. Keterangan laik etik No: 400/148/K.3/302/2016 diperoleh dari komisi etik penelitian kesehatan RSUDDr.Saiful Anwar, dan informed consent tertulis didapat dari seluruh pasien.

Subjek

Subjek penelitian adalah pasien dengan lesi intratorakal yang membutuhkan dukungan diagnosis menggunakan biopsi tuntunan USG yang dilakukan selama bulan November-Desember 2016 di Departemen Radiologi RSUD Dr. Saiful Anwar Malang. Terdapat 26 pasien dilibatkan dalam 
penelitian ini. Rerata usia pasien adalah $57,2 \pm 12,4$ tahun, usia termuda sampel adalah 18 tahun dan yang usia yang tertua adalah 74 tahun. Dari 26 pasien terdapat 15 orang laki-laki $(57,7 \%)$ dan 11 orang perempuan $(42,3 \%)$.

\section{Evaluasi Imaging}

Pasien dipastikan memiliki radiografi toraks AP-lateral dan atau hasil pemeriksaan CT scan toraks paling lama satu bulan dari tanggal tindakan biopsi, yang bisa memberikan petunjuk apakah lesi berada di perifer atau sentral, dan berapa ukuran bagian lesi yang menempel dinding dada sebelum dilakukan biopsi. Lesi bisa berasal dari paru, pleura maupun mediastinum. Posisi lesi dikategorikan dengan kombinasi sela iga dan kedudukannya, area sela iga 1 4, sela iga 5-9 dan sela iga 10-12, dan masing masing level dibagi juga sesuai anterior, lateral dan posterior. Dilakukan pula pengukuran pada bagian lesi yang menempel dinding dada, dikategorikan ukuran $<2 \mathrm{~cm}, 2-5 \mathrm{~cm}$ dan $>5 \mathrm{~cm}$. Kemudian dilakukan pemeriksaan dengan USG oleh ahli radiologi untuk menentukan karakteristik lesi. Bentuk lesi dikategorikan menjadi reguler dan irreguler berdasarkan bentuk batas lesi yang bisa tervisualisasi. Ekhogenitas ditentukan dari visualisasi lesi dalam skala abu-abu dan dikategorikan menjadi hipoekhoik tanpa bintik-bintik hiperekhoik, hipoekhoik dengan bintik- bintik hiperekhoik $\leq 25 \%$ area, serta hipoekhoik dengan bintik-bintik hiperekhoik > 25\% area. ${ }^{7}$ Komponen lesi ditentukan dari bagian terbanyak (> 60\%) area lesi dan dikategorikan menjadi solid atau kistik. Vaskularisasi ditentukan dengan aliran pembuluh darah intra lesi yang dinilai dengan USG colour Doppler, dan dikategorikan menjadi $\leq 2$ pembuluh darah tervisualisasi dalam lesi $>2$ pembuluh darah tervisualisasi dalam lesi. ${ }^{7}$
Prosedur biopsi dengan penuntun USG diawali dengan melokalisir titik pungsi dan menentukan kedalaman titik pungsi, selanjutnya diberi titik marker permukaan kulit pada sela iga. Pasien saat dilakukan biopsi harus tidak dalam keadaan umum yang buruk yang memerlukan penanganan khusus. Posisi pasien bisa dalam kondisi berbaring telentang atau telungkup atau dengan posisi duduk, tergantung lokasi dari lesi intratorakal berdasarkan hasil CT scan dan atau radiografi toraks, manuver pemeriksa dan kenyamanan pasien.Alat USG yang digunakan adalah Epiq $5 \mathrm{G}$ Philips tranduser kurvilinier 3-5 $\mathrm{MHz}$ dan tranduser linier $7-13 \mathrm{MHz}$.

\section{Biopsi Jarum Halus-tuntunan USG}

Setelah disinfeksi dengan betadine atau alkohol, jarum halus diinsersi melalu titik marker sedalam ukuran yang telah diperoleh sebelumnya. Jarum yang digunakan adalah jarum halus 23 atau 25 Gauge untuk lesi dengan kedalaman $<3 \mathrm{~cm}$ dan jarum kanul pungsi lumbal dengan mandrin untuk lesi dengan kedalaman $>3$ $\mathrm{cm}$. Selanjutnya tranduser USG kembali ditempelkan dekat dengan jarum yang telah diinsersi untuk melihat ketepatan arah insersi jarum dengan visualisasi real time, bila ujung jarum tepat di lesi target bisa dilakukan teknik aspirasi atau non aspirasi. Hasil biopsi dihapuskan di kaca objek, kemudian dilakukan fiksasi kering sebelum dilakukan pewamaan Diff Quik® atau fiksasi menggunakan alkohol 95\% sebelum dilakukan pewarnaan hematoxyllineosin. Hasil ambilan yang adekuat adalah bila dalam hapusan tersebut didapat sel-sel dengan jumlah yang cukup disertai gambaran sitomorfologi yang konsisten atau menyokong diagnosis klinis atau radiologis.

\section{Analisis Data}

Untuk mengetahui pengaruh antara karakteristik lesi terhadap efektifitas biopsi 
jarum halus transtorakal dengan penuntun USG, dilakukan uji bivariat, bermakna bila $p$ $<0,05$. Bila terdapat beberapa variabel yang memiliki nilai kemaknaan, maka dilakukan uji multivariat regresi logistik untuk menentukan variabel yang paling berpengaruh terhadap keberhasilan ambilan sampel.

\section{Hasil}

Posisi lesi terbanyak berada di anterior atas yaitu $8(30,8 \%)$ pasien, dan tidak ada di anterior bawah. Ukuran lesi yang menempel dinding dada pada kelompok ukuran $<2 \mathrm{~cm}$ didapatkan pada $1(3,8 \%)$ pasien, kelompok ukuran 2-5 cm sebanyak 13 (50\%) pasien dan kelompok $>5 \mathrm{~cm}$ terdapat pada 12 $(46,2 \%)$ pasien. Bentuk lesi yang reguler didapatkan pada 22 (84,6\%) pasien, sedangkan yang ireguler sebanyak 4 $(15,4 \%)$ pasien. Contoh hasil USG atas karakteristik lesi terkait bentuk lesi tercantum pada Gambar 1. Ekhogenitas lesi pada kelompok hipoekhoik tanpa bintik hiperekhoik diperoleh pada 20 (76,9\%) pasien, dan pada kelompok hipoekhoik dengan bintik hiperekhoik $\leq 25 \%$ dan $>25 \%$ masing-masing dengan jumlah pasien yang sama yaitu $3(11,5 \%)$ pasien. Contoh hasil USG terkait karakteristik ekhogenitas lesi dapat dilihat pada Gambar 2. Komponen dominan lesi yang didapatkan pada penelitian ini adalah seluruhnya (100\%) solid, tidak ada komponen kistik. Adanya vaskularisasi lesi $\leq 2$ pembuluh darah tervisualisasi didapatkan pada 20 (76,9\%) pasien, sedangkan vaskularisasi lesi $>2$ pembuluh darah tervisualisasi ditemukan pada 6 (23,1\%) pasien. Contoh hasil pemeriksaan USG terkait vaskularisasi ada pada Gambar 3. Seluruh hasil pengambilan data dirangkum dalam Tabel 1 .

Hasil akhir diagnosis patologi yang didapat dari data seluruh pasien sampel adalah tumor paru sebanyak $14(53,8 \%)$ pasien, tumor mediastinum $3(11,5 \%)$ pasien dan diagnosis lain sebanyak $9(34,6 \%)$ pasien. Diagnosis lain ini meliputi hasil ambilan sampel yang jinak sebanyak 5 pasien dan ambilan sampel yang tidak adekuat untuk dinilai sitopatologi nya sebanyak 4 pasien.
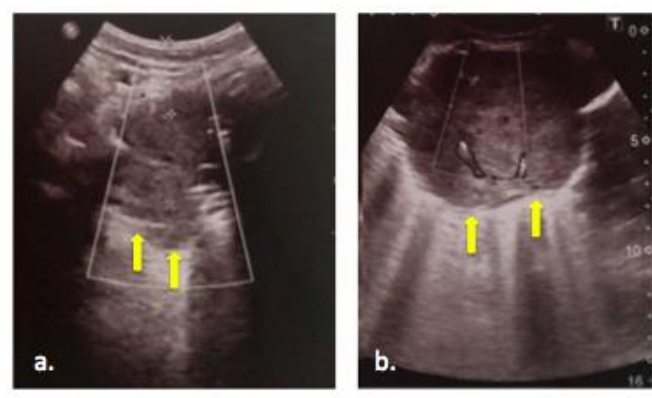

Gambar 1. Hasil USG pada 2 orang pasien. Keterangan: a. Lesi dengan bentuk irreguler (panah kuning)

b. Lesi dengan bentuk reguler (panah kuning)
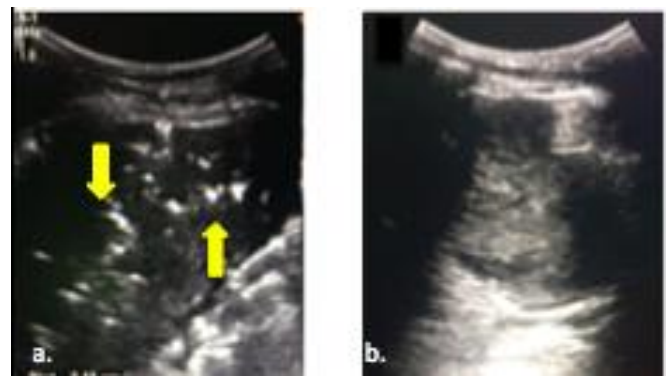

Gambar 2. Hasil USG pada 2 orang pasien. Keterangan:

a. Lesi dengan bintik hiperechoik > 25\% (panah kuning)

b. Lesi tanpa bintik hiperechoik

Analisis hubungan seluruh variabel karakteristik lesi dengan adekuasi ambilan sampel dapatdisusun dalam T abel 2. 
Tabel 1. Karakteristik dasar subjek

\begin{tabular}{|c|c|}
\hline & $\mathrm{n}(\%)$ \\
\hline \multicolumn{2}{|l|}{ Jenis Kelamin } \\
\hline Laki-laki & $15(57,7)$ \\
\hline Perempuan & $11(42,3)$ \\
\hline \multicolumn{2}{|l|}{ Posisi Lesi } \\
\hline A1: Level iga 1 - 4 anterior & $8(30,8)$ \\
\hline A2: Level iga 1-4 lateral & $2(7,7)$ \\
\hline A3: Level iga 1-4 posterior & $3(11,5)$ \\
\hline B1: Level iga 5-9 anterior & $4(15,4)$ \\
\hline B2: Level iga 5-9 lateral & $4(15,4)$ \\
\hline B3: Level iga 5-9 posterior & $1(3,8)$ \\
\hline C1: Level iga 10-12 anterior & $0(0)$ \\
\hline C2: Level iga 10-12 lateral & $1(3,8)$ \\
\hline C3: Level iga $10-12$ posterior & $3(11,5)$ \\
\hline \multicolumn{2}{|l|}{ Ukuran Lesi yang Menempel Dinding Dada } \\
\hline$<2 \mathrm{~cm}$ & $1(3,8)$ \\
\hline $2-5 \mathrm{~cm}$ & $13(50,0)$ \\
\hline$>5 \mathrm{~cm}$ & $12(46,2)$ \\
\hline \multicolumn{2}{|l|}{ Bentuk Lesi } \\
\hline Reguler & $22(84,6)$ \\
\hline Ireguler & $4(15,4)$ \\
\hline Ekhogenitas Lesi & $20(76,9)$ \\
\hline Hipoekhoik tanpa bintik hiperekhoik & $3(11,5)$ \\
\hline $\begin{array}{l}\text { Hipoekhoik dengan bintik hiperekhoik } \leq 25 \% \\
\text { Hipoekhoik dengan bintik hiperekhoik }>25 \%\end{array}$ & $3(11,5)$ \\
\hline \multicolumn{2}{|l|}{ Komponen Dominan Lesi } \\
\hline Solid & $26(100)$ \\
\hline Kistik & 0 \\
\hline \multicolumn{2}{|l|}{ Vaskularisasi Lesi } \\
\hline$\leq 2$ vaskular tervisualisasi & $20(76,9)$ \\
\hline > 2 vaskular tervisualisai & $6(23,1)$ \\
\hline \multicolumn{2}{|l|}{ Adekuasi Ambilan Jaringan } \\
\hline Adekuat & $22(84,6)$ \\
\hline Inadekuat & $4(15,4)$ \\
\hline
\end{tabular}

Tabel 2. Rekapitulasi hubungan karakteristik lesi dengan adekuasi ambilan sampel sitologi

\begin{tabular}{|c|c|c|c|}
\hline \multirow[t]{2}{*}{ Variabel } & \multicolumn{2}{|c|}{ Adekuasi Ambilan Sampel } & \multirow[t]{2}{*}{ Nilai $p$} \\
\hline & Adekuat & Inadekuat & \\
\hline \multicolumn{4}{|l|}{ Posisi lesi } \\
\hline Anterior & $9(75 \%)$ & $3(25 \%)$ & 0,306 \\
\hline Non anterior & $13(92,9 \%)$ & $1(7,1 \%)$ & \\
\hline \multicolumn{4}{|l|}{ Ukuran lesi yang menempel dinding dada } \\
\hline$<2 \mathrm{~cm}$ & $1(3,8 \%)$ & $0(0,0 \%)$ & 1,0 \\
\hline $2-5 \mathrm{~cm}$ & $11(84,6 \%)$ & $2(15,4 \%)$ & \\
\hline$>5 \mathrm{~cm}$ & $10(83,3 \%)$ & $2(16,7 \%)$ & \\
\hline \multicolumn{4}{|l|}{ Bentuk lesi } \\
\hline Irreguler & $3(75,0 \%)$ & $1(25,0 \%)$ & 0,511 \\
\hline Reguler & $19(86,4 \%)$ & $3(13,6 \%)$ & \\
\hline \multicolumn{4}{|l|}{ Ekhogenitas lesi } \\
\hline Hipoekhoik tanpa bintik hiperekhoik & $18(90,0 \%)$ & $2(10, \%)$ & 0,067 \\
\hline Hipoekhoik dengan bintik hiperekhoik $\leq 25 \%$ & $1(33,3 \%)$ & $2(66,7 \%)$ & \\
\hline Hipoekhoik dengan bintik hiperekhoik > 25\% & $3(100 \%)$ & $0(0,0 \%)$ & \\
\hline
\end{tabular}




\begin{tabular}{|c|c|c|c|}
\hline \multicolumn{4}{|l|}{ Vaskularisasi lesi } \\
\hline$\leq 2$ vaskular tervisualisasi & $17(85,0 \%)$ & $3(15,0 \%)$ & 1,0 \\
\hline$>2$ vaskular tervisualisai & $5(83,3 \%)$ & $1(16,7 \%)$ & \\
\hline
\end{tabular}

\section{Pembahasan}

Variabel karakteristik lesi meliputi posisi lesi, ukuran lesi yang menempel dinding dada, bentuk lesi, ekhogenitas lesi, komponen dominan lesi dan vaskularisasi lesi. Tidak ada variabel karakteristik lesi ini yang memiliki hubungan dengan adekuasi ambilan sampel sitologi.

Keberhasilan diagnosis patologi biopsi jarum halus yang dituntun USG pada penelitian ini mencapai $84,6 \% \quad(22 / 26)$, termasuk pada lesi berdiameter kecil $<2 \mathrm{~cm}$. Hal ini sesuai dengan hasil penelitian oleh DiBardino dkk bahwa aspirasi jarum transtorakal dengan penuntun USG memiliki keberhasilan sampai $88,7 \% .{ }^{8}$ Penelitianpenelitian lainnya menyebutkan angka keberhasilan yang hampir sama antara biopsi tuntunan USG dengan tuntunan CT scan. 9,10 Penelitian oleh Sheth dkk. juga menunjukkan keberhasilan pengambilan sampel dengan ukuran kecil $<2 \mathrm{~cm}$ pada biopsi tuntunan USG. ${ }^{5}$ Rekomendasi dari British Thoracic Society menyebutkan sebisa mungkin biopsi paru transtorakal perkutan menggunakan tuntunan USG sebagai modalitas yang paling aman, cepat dan lebih murah. ${ }^{4}$

Penggunaan jarum halus dalam penelitian ini juga memiliki hasil yang baik, sesuai dengan penelitian oleh Diacon dkk. yang membandingkan keberhasilan biopsi jarum halus dengan cutting needle biopsy (CNB), bahwa jarum halus secara signifikan lebih baik keberhasilannya dibanding CNB pada kasus karsinoma paru ( $95 \%$ vs. $81 \%)$, namun CNB lebih superior untuk kasus tumor non karsinoma dan lesi jinak. ${ }^{11}$ Sensitifitas biopsy jarum halus untuk mendapatkan hasil ambilan malignansi seharusnya dalam kisaran $85-90 \%$ pada lesi $>2 \mathrm{~cm} .{ }^{4}$

Akurasi diagnostik dengan aspirasi jarum halus tergantung pada ukuran dan lokasi lesi, pengalaman operator, tipe jarum, pilihan teknik biopsi, dan keberadaan expertise sitopatologi. ${ }^{4}$ Sebanyak $75 \%$ lesi adenocarcinoma berada di perifer paru, karena berasal dari epitel bronkhioli dan alveoli. ${ }^{12}$ Massa paru perifer tampil sebagai massa berbatas tegas dengan ekhogenitas yang bervariasi, tersering hipoekhogenik, yang dikelilingi jaringan paru teraerasi dengan refleksifitas yang tinggi. ${ }^{1}$

Posisi lesi intratorakal perifer memiliki tantangan tersendiri dalam tindakan biopsi mengingat kendala anatomis, absorpsi gelombang suara oleh tulang, seperti sternum, skapula dan vertebra juga membuat area dibelakang tulang-tulang ini sulit ditampilkan. Terkadang teknik aspirasi yang baik bisa mengatasi kendala ini. ${ }^{6}$ Posisi lesi yang berada di dekat struktur jantung, vaskular besar dan diafragma juga memiliki tantangan tersendiri bagi operator. Namun demikian, dari hasil penelitian ini tidak ditemukan adanya hubungan antara posisi lesi dengan adekuasi ambilan sampel sitologi.

Sensitifitas biopsi jarum halus untuk mendapatkan hasil ambilan malignansi seharusnya dalam kisaran $85-90 \%$ pada lesi lebih dari $2 \mathrm{~cm} .{ }^{4}$ Namun hasil dari penelitian ini tidak menemukan hubungan antara ukuran lesi yang menempel pada dinding dada dengan adekuasi ambilan sampel sitologi.

Dari seluruh ambilan sampel sitologi yang adekuat, lesi terkecil (diameter 1,5 cm) termasuk di dalamnya. Dari 12 pasien dengan ukuran lesi $>5 \mathrm{~cm}$, terdapat 10 $(83,3 \%)$ pasien yang ambilan sampel sitologi nya adekuat. Hal ini bisa menunjukkan bahwa lesi berukuran kecil masih bisa dilakukan biopsi jarum halus dengan tuntunan USG. Selain itu, bisa dikatakan 
pula bahwa lesi berukuran lebih besar tidak selalu ambilan sampel sitologinya adekuat.

Lesi inflamasi kronik kebanyakan menunjukkan bentuk kerucut dengan beberapa fokal hiperechoik di dalam massa hipoekhoik. Titik hiperekhoik menunjukkan adanya udara dalam bronkhus kecil. Secara anatomis, inflamasi pulmonal biasanya mengenai satu atau sebagian segmen paru, yang menyebabkan bentuk mengerucut oleh karena konstriksi bronkhial.7 Pada literatur lain disebutkan pneumonia memiliki bentuk tepi yang irreguler, bergerigi dan kadang tidak tegas. ${ }^{2}$ Kebanyakan lesi maligna menunjukkan massa bentuk membulat disebabkan pertumbuhan ekspansi, tanpa titik hiperekhoik didalamnya, biasanya berbatas tegas dengan jaringan paru nomal., 2,7 Penelitian ini tidak menemukan adanya hubungan antara bentuk lesi dengan adekuasi ambilan sampel sitologi.

Bila jaringan paru mengalami inflamasi, maka akan terjadi hiperemia, edema, nekrosis fokal, atau hiperplasia. Bronkhus yang berdilatasi dan berkelok dengan udara di dalamnya terjadi karena obstruksi oleh material inflamasi. Pada USG dilatasi ini menyerupai tanda 'sama dengan $(=)$ '. 7 Penelitian ini tidak menemukan hubungan antara ekhogenitas lesi dengan adekuasi ambilan sampel sitologi.

Pada stadium awal penyembuhan inflamasi, banyak pembuluh darah terbentuk di dalam lesi. Kebanyakan karsinoma paru juga membentuk pembuluh darah yang banyak, sehingga membuat color Doppler memiliki nilai yang kecil dalam membedakan lesi paru benign atau maligna. Namun demikian, dengan penggunaan USG color Doppler, pembuluh darah besar dapat tervisualisasi, sehingga pendarahan bisa dihindani, dan ambilan sampel sitologi yang baik dapat diperoleh dari kebanyakan pasien. ${ }^{7}$ Namun demikian, penelitian ini tidak menemukan hubungan antara vaskularisasi lesi dengan adekuasi ambilan sampel sitologi.

\section{Kesimpulan}

Tidak ada hubungan antara karakteristik lesi (posisi, ukuran, bentuk, ekhogenitas, komponen dominan, vaskularisasi lesi) terhadap adekuasi ambilan sampel sitologi pada tindakan biopsi jarum halus transtorakal-tuntunan USG. Namun demikian dari penelitian ini didapatkan bahwa keberhasilan diagnosis patologi dari tindakan biopsi jarum halus yang dituntun oleh USG pada penelitian ini mencapai $84,6 \%$.

\section{Ucapan terima kasih}

Penulis berterimakasih kepada Departemen Patologi Anatomi RSUD Dr. Saiful Anwar Malang, dr. Vally Wulani, SpRad.(K) dan Prof. Dr. Yuyun Yueniwati, SpRad.(K) atas segala dukungannya sehingga penelitian ini bisa terlaksana.

\section{Daftar Pustaka}

1. Rednic N, Orasan O. Subpleural Lung Tumors Ultrasonography. Medical Ultrasonography. 2010; (12):81-7.

2. Mathis G. Chest Sonography. 3rd Edition. Mathis G (Editor). Berlin: Springer. 2011. P.187-210.

3. Birchard KR. Transthoracic Needle Biopsy. Semin Intervent Radiol (Online). 2011; 28(1):87-97. Available from:

http://www.thiemeconnect.de/DOI/DOI? 10.1055/s-0031-1273943.

4. Manhire A, Charig M, Clelland C, Gleeson $F$, Miller R, Moss $H$, et al. Guidelines for Radiologically Guided Lung Biopsy. Thorax. 2003; 58:920-36.

5. Jarmakani $M$, Duguay $S$, Rust $K$, Conner K, Wagner JM. Ultrasound 
Versus Computed Tomographic Guidance for Percutaneous Biopsy of Chest Lesions. J Ultrasound Med. 2016;35(9):1865-72.

6. Beckh S. Indications, Technical Prerequisites and Investigation Procedure. In: Chest Sonography. Springer. 2008. P. 1-9.

7. Yang RJ, Yang YL, Ruan LT, Yuan LJ, Chao LJ, Chen S, et al. Clinical Value of Ultrasound-Guided Percutaneous Biopsy of Pulmonary Lesions. Genet Mol Res. 2015;14(2):3784-90.

8. Di Bardino DM, Yarmus LB, Semaan RW.T ransthoracic Needle Biopsy of the Lung. J Thorac Dis. 2015;7:S304-16.

9. Sconfienza LM, Mauri G, Grossi F, Truini M, Serafini G, Sardanelli F, et al. Pleural and Peripheral Lung Lesions: Comparison of US- and CT-Guided Biopsy. (Online). Radiology. 2013; 266
(3):930-5. Available from: http://pubs.rsna.org/doi/10.1148/radiol. 12112077.

10. Khosla R, McLean A, Smith J. Ultrasound-Guided Versus Computed Tomography-Scan Guided Biopsy of Pleural-Based Lung Lesions.(Online). Lung India 2016; 33(5):487. Available from:http://www.lungindia.com/text.asp ?2016/33/5/487/188961.

11. Diacon $A H$, Theron J, Schubert $P$, Brundyn K, Louw M, Wright CA, et al. Ultrasound-Assisted Transthoracic Biopsy: Fine-Needle Aspiration or Cutting-Needle Biopsy?. Eur Respir J. 2007;29(2):357-62.

12. Webb WR, Higgins CB. Thoracic Imaging, Pulmonary and Cardiovascular. Radiology. $2^{\text {nd }}$ Edition. Philadelphia: Lippincott Williams \& Wilkins. 2011;69-77. 